\title{
U2 Los secretos de El Paraíso de Armando Salazar
}

\author{
Ricardo Roque Baldovinos \\ Universidad Centroamericana "José Simeón Cañas", UCA
}

Con esta publicación, la editorial de la Universidad Centroamericana relanza su colección "Testigos de la historia", que tuvo un peso importante en difundir títulos de la llamada literatura testimonial en El Salvador durante las décadas de 1980 y 1990. Esta literatura, sin embargo, ha adquirido en el presente un importante giro de la denuncia a la memoria. En la medida que el conflicto armado se aleja en el tiempo, lo testimonial se convierte en un espacio para construir una memoria que extraiga lecciones para el presente de un pasado a la vez cruento y esperanzador.

"Testigos de la historia" se revive pues con una obra que tiene calidad de contenido pero también de escritura. Los secretos de El Paraíso (2016) reconstruye un hito en el conflicto armado de El Salvador, la destrucción del cuartel de la Cuarta Brigada de Infantería, en El Paraíso, Chalatenango, por obra de un sorpresivo y espectacular ataque de fuerzas combinadas del FMLN que tuvo lugar en diciembre de 1983. Armando Salazar, el autor, no es un historiador de oficio; sin embargo, el libro que nos presenta supone un esfuerzo de investigación admirable que ha requerido de especial creatividad en la reconstrucción de los hechos desde la perspectiva insurgente. ¿Cómo poder restituir la totalidad de una acción en un modo de operar que suponía la máxima compartimentación? A través de una intensa labor de entrevistas a los sujetos que sirvieron de engranajes de la maquinaria de la operación guerrillera. ¿Cómo concatenar y hacer legible ese inmenso caudal de información y vivencias? A través de un ejercicio de escritura diestro, cuyo resultado es un libro que no sólo se deja leer, si no que atrapa desde el primer momento.

Otros han comentado desde la perspectiva de la disciplina histórica el significado de esta obra. Por ello, me centraré más bien en su dimensión "literaria", pero sobre una escritura que no tiene sólo implicaciones estéticas sino epistémicas y políticas. Como mucha de 
la literatura testimonial Los secretos de El Paraíso desafía las clasificaciones genéricas. Puede verse como historia, crónica o, incluso, literatura, pues hay partes donde la ficcionalización, la puesta en tiempo, espacio y personajes de los sucesos narrados, son impecables, digna de la mejor escritura novelística. Y no lo digo con ironía, como una descalificación sino todo lo contrario; como un reconocimiento a un esfuerzo de hacer historia que se toma en serio la escritura de la misma.

Es así como una de las implicaciones más importantes de esta escritura se revela si analizamos la dimensión "épica" de la obra.
Y empleo el término más allá de los clisés gastados, de identificar lo épico como algo que habla de guerra y batallas, o de personajes colectivos. ¿En qué sentido, pues, esta obra aspira a una construcción de sentido que le podríamos llamar épica? Esto lo comprenderemos mejor si recordamos la reflexión clásica sobe el tema, presente en Teoría de la novela, que escribió el filósofo marxista húngaro Georg Lukács cuando todavía no era marxista. Para este autor, lo propio de la épica es construir un sujeto colectivo donde individuo y colectividad se fusionan. Lukács (2010) lo dice de una manera muy hermosa en las primeras líneas:

Felices los tiempos en que el cielo estrellado es el mapa de todos los caminos posibles, tiempos en que los senderos se iluminan bajo la luz de las estrellas! (Sic.) Todo en aquellos tiempos es nuevo y, a la vez, familiar; los hombres salen en busca de aventuras pero nunca se hallan en soledad. El universo es vasto pero es como el propio hogar, pues el fuego que arde en las almas es de la misma naturaleza que el de las estrellas. (p. 21)

En nuestro libro, luego de una intrincada relación de los preparativos de la operación, se alcanza el momento épico en la proeza militar de la toma del cuartel. La caída del cuartel de El Paraíso es el "asalto al paraíso", un momento de plenitud, de epifanía del colectivo épicorevolucionario. La narración elige para ello el momento en que las tropas de la Fuerza Especial (FES) descienden para realizar su misión:

Los pensamientos y sentimientos de los comandos de la FES se entrecruzaban en el momento en que cada escuadra rompió la formación para iniciar esa marcha rumbo a un hecho trascendental de la lucha revolucionaria salvadoreña. 
Sus vidas, sus fuerzas, su inteligencia, sus sueños, sus habilidades y conocimientos, sus querencias, sus debilidades o carencias se sintetizaban en cada paso, haciendo un solo cuerpo en marcha. (Salazar, 2016, p. 260)

Se han transformado en un cuerpo colectivo compacto, sin fisuras. Y esta apoteosis es el resultado de una progresión narrativa donde este momento aparece como la culminación necesaria.

En este sentido de fusión de individuo y colectividad del sujeto, podemos entender otro rasgo de la épica según Lukács (2010): la ausencia de ironía. Y no lo digo tampoco en un sentido negativo. Falta de ironía no se refiere a falta de humor, o falta de imaginación, en Los secretos del paraíso éstos abundan. Me refiero más bien a la ausencia de distancia entre el tema y el lenguaje. Un rasgo desconcertante del libro es que está referido con un vocabulario político que pareciera haber sido trasplantado intacto de la época. Es un vocabulario del cual el narrador no se distancia para asumir uno más contemporáneo. Así llegamos a un rasgo a la vez esencial y paradójico de la arquitectura verbal del libro. Salta a la vista el cuidado y riguroso ensamblaje que permite articular la voz del narrador (la portadora de la autoridad central del universo reconstruido) con un amplio coro de voces de los partícipes de la hazaña.
Es admirable porque se logra una perfecta progresión del relato de los hechos, con la inserción de las perspectivas y vivencias de muchas personas. Uno se sentiría tentado a hablar, ante esto, de una estructura en contrapunto. Mas si nos tomamos en serio el símil musical, veríamos que esto no sería del todo exacto. El contrapunto es el arte de combinar melodías diferentes. $Y$ a lo largo del libro, aun cuando las diversas voces tienen su timbre característico, se mueven dentro de la misma tonalidad. Hasta las voces de los antagonistas sirven para confirmar, en negativo, lo fundamental del sentido del relato principal. No se puede decir tampoco que se trate de un coro al unísono, de una monodia. Sería más exacto afirmar, para seguir la analogía musical, que estamos ante una homofonía, una misma melodía cantada con ligeras variantes pero que no exceden la tonalidad dominante.

Una crítica fácil al libro de Salazar sería denunciar la casi total ausencia de voces "disidentes", principalmente de los enemigos del ejército, pero creo que habría que preguntarse si realmente esas voces tienen cabida en la concepción del libro. Si en una épica donde se revela el sujeto revolucionario que se encarna admite disonancia posible. Estamos, pues, ante una decisión de concepción y no de construcción, es decir de inventio y no de dispositio, para usar la terminología de la retórica clásica. 
Consecuentemente, si la construcción de la obra es congruente con su designio, es hacia la concepción de la agencia histórica que debemos enfocar nuestros esfuerzos críticos, si queremos estar a la altura de la calidad de la obra que se nos entrega. En otras palabras, si queremos ser fieles al espíritu de esta colección "Testigos de la historia", que se inspiró en las ideas de Ellacuría, tenemos que historizar y pensar cuáles pueden ser los alcances de revivir un suceso en la forma que nos lo presenta Los secretos de El Paraíso.

Cabría entonces preguntarnos qué sentido tiene esa transparencia épica, esa absoluta fusión entre individuo y colectividad, en tiempos de gran fragmentación y violencia como los actuales, donde las perspectivas de redención parecen postergadas a un futuro bastante distante. ¿Será el sustento de una narrativa, que parece estarse consolidando, que se presta a legitimar el poder de quienes se declaran herederos directos e intérpretes exclusivos de la plenitud épica? ¿O será mejor recordar que el epos (el sujeto épico) sólo fue posible por un demos, es decir por ese vendaval democrático capaz que despertó una voluntad popular de quienes dejaron de sentirse condenados a la impotencia? Los secretos de El Paraíso aporta abundante material para ensayar esta última lectura. Pues, más que arcadias que nos consuelen en la nostalgia de mejores tiempos pretéritos, necesitamos utopías, nuevas inteligencias que nos equipen para el largo camino a través de la opacidad que nos entrega el presente.

\section{Referencias}

- Lukács, G. (2010). Teoría de la novela, un ensayo histórico filosófico sobre las formas de la gran literatura épica. Buenos Aires, Argentina: Ediciones Godot.

- Salazar, A. (2016). Los secretos de El Paraíso. Asalto a la Cuarta Brigada, Chalatenango. San Salvador: UCA Editores. 


\section{Normas de publicación en Realidad}

Realidad publica ensayos, notas y reseñas en idioma español relacionados con las diversas disciplinas de las ciencias sociales y las humanidades. Los artículos publicados por Realidad podrán ser difundidos posteriormente en cualquier medio, siempre y cuando se indiquen los datos de publicación original.

La publicación de originales se rige por medio de las siguientes normas:

\section{Presentación de artículos, notas y reseñas}

Los trabajos se remitirán en formato Word como documentos adjuntos de correo electrónico a la siguiente dirección: realidad.director@uca.edu.sv

O a la dirección postal:

Ricardo Roque Baldovinos

Director de Realidad, Revista de Ciencias Sociales y Humanidades

Apartado Postal (01) 168

San Salvador

El Salvador

\section{Presentación de ensayos}

a. El ensayo deberá ser original, inédito y de alta calidad académica.

b. El ensayo deberá ir precedido de dos resúmenes de entre 100 y 150 palabras cada uno: el primero, se escribirá en español y el segundo en inglés. También deberá llevar al menos 6 palabras claves en esos dos idiomas.

c. El nombre del autor o autores irá consignado después del título del mismo. A continuación, se incluirá el nombre de la universidad o la institución de afiliación.

d. Las palabras en una lengua diferente a la de la redacción del texto aparecerán en cursiva; asimismo se empleará este tipo de letra para resaltar alguna palabra clave, y cuando esto suceda en un fragmento textual en cursiva, se procederá de modo contrario, i.e., destacar la palabra clave en caracteres normales.

e. Las figuras, ilustraciones y tablas deberán ir numeradas con cifras arábigas y con un pie indicando su contenido; se incluirán preferentemente en el documento de Word. De no ser posible, se adjuntarán en archivos separados.

f. La extensión mínima para los ensayos es de 35,000 caracteres y la máxima de 75,000. Para los notas y las reseñas la extensión máxima es de 
25,000 caracteres. En el conteo de caracteres se incluyen notan y se excluyen espacios en blanco.

\subsection{Tipo y tamaño de letra}

Los originales se presentarán con justificación completa en letra Arial 11 puntos para el texto, la bibliografía, las citas y los resúmenes o abstracts. La letra Arial 10 puntos se requiere para las notas, números sobrescritos, tablas y figuras.

\section{a) Apartados y subapartados}

Los títulos de los apartados se presentarán en negrita, numerados con cifras arábigas, y separados por dos líneas del texto anterior y por una línea del texto siguiente. En cuanto a los títulos de los subapartados, se anotarán en negritas y serán nuevamente numerados (v. gr., 1.1., 1.2., 1.3.), debiendo separarse por una línea tanto del texto que antecede como del texto subsiguiente. Los niveles siguientes, que deberán evitarse en lo posible, serán numerados igualmente con cifras arábigas y se escribirán en texto común (v. gr., 1.1.1., 1.1.2.; 1.1.1.1., 1.1.1.2.).

\section{b) Referencias bibliográficas}

Los autores enviarán sus colaboraciones en el sistemas en referencias bibliográficas APA.

\section{Presentación de comentarios y recensiones bibliográficas}

Tanto los comentarios como las recensiones se regirán por los mismos requisitos en cuanto al tipo y el tamaño de letra. La extensión mínima de los comentarios es de 5,000 caracteres y la máxima, de 25,000. Los comentarios no requieren resumen. Las recensiones de libros irán encabezadas por la ficha técnica del libro (Autor o autores, Título del libro, Ciudad, Año, número de páginas. Número de ISBN). Tendrán un máximo de 12,000 caracteres. Al final de la recensión, se incluirá el nombre del autor o autora de la misma y el nombre de la universidad o institución de procedencia.

\section{Criterios de publicación}

Todos los trabajos sometidos serán arbitrados por pares en los sistemas visto, ciego o doble ciego. No se entablará correspondencia por trabajos no solicitados. 


\section{REALIDAD - CUPÓN DE SUSCRIPCIÓN ANUAL POR 2 NÚMEROS}

Primera vez Renovación

Última fecha de suscripción

A partir del número

Nombre

Tel.

Dirección

Ciudad Código postal

Departamento o Estado País

Dirección electrónica

Edad

Escolaridad

Sexo: $\mathrm{H} \square \mathrm{M} \square$ Profesión

Enviar cupón de suscripción al fax (503) 22106650 o enviarlo escaneado a distpubli@ued.uca.edu.sv

o a la siguiente dirección: Distribuidora de Publicaciones UCA, apartado postal 01-575, San Salvador,

El Salvador, Centroamérica.

\section{COSTOS DE SUSCRIPCIÓN ANUAL}

(en dólares estadounidenses; incluye gastos de envío)

\$12.00 para El Salvador, personal $* \$ 16.00$ para El Salvador, por correo

* \$35.00 para Centroamérica y Panamá * \$65.00 para Norte y Suramérica

Formas de pago

*\$80.00 para Europa y otras regiones

(a) En El Salvador:

$\checkmark$ personal (directamente)

$\checkmark$ por depósito. Solicitar la información a distpubli@ued.uca.edu.sv

o a los teléfonos (503) 22106650 (directo) o al 22106600 extensiones 240 o 241 o 242.

(b) Desde el extranjero:

$\checkmark$ Por giro postal. El cheque debe emitirse a nombre de la Universidad Centroamericana José Simeón Cañas. Además debe tener representación en Estados Unidos. El cheque debe enviarse a: Distribuidora de Publicaciones UCA, apartado postal 01-575, San Salvador, El Salvador, Centroamérica.

$\checkmark \quad$ Por transferencia bancaria. Solicitar la información a distpubli@ued.uca.edu.sv 